\title{
Health and greening the city
}

\section{J R Ashton}

\section{See page 913}

T kyo is one of the world's great new metropolitan areas; when I firs visited it, it reminded me powerfully of Fritz Lang's prescient classic Metropolis. Space is at an absolute premium and conducting the normal routines of everyday life can seem like a major challenge. The contemporary public health issues are mostly to be found there.

Fortunately for Tokyo and its citizens, Takehito Takano and his group at the Graduate School of Tokyo Medical and Dental University are well on the case and have been for over 10 years. Working within the framework of the WHO Healthy Cities initiative,[1] they have thrown light on pressing problems in novel and lateral ways. This group is really "out of the box", while grounded in the classic epidemiological methods.
Their latest offering is a cohort study of elderly Tokyo citizens to establish whether having ready access to green space affects longevity. In summary it seems to, and the factors of walkable green streets and spaces near the residence and that of having a positive attitude to one's own community both came out with positive predictive values for survival over the following five years.

The implications of this, and of this genre of work for the reinvigoration of town planning and its connections to public health are obvious (Liverpool, where I am writing this piece from, had not only the first full time city medical officer in William Henry Duncan but also the first university department of town planning, and this was no coincidence).
However, we must remind ourselves that to the biomedical strand of public health and the environmental strand of town planning we also need the behavioural and political strand when considering these kinds of questions. Throwing green space at people may well not work unless they have some sense of ownership power and control, hence the significance of the finding relating to citizen's attitude to their community.

Professor Takano visited Liverpool in the late 1980s to study William Henry Duncan's legacy when he was embarking on his Healthy Cities research programme. William Henry would have been more than proud at the results.

J Epidemiol Community Health 2002;56:896

\section{Author's affiliations}

J R Ashton, CBE, NHS Executive North West RO, 930-932 Birchwood Boulevard, Millennium Park, Birchwood, Warrington WA3 7QN, UK

Correspondence to: Professor J R Ashton J.Ashton@btinternet.com

\section{REFERENCE}

1 Ashton J, ed. Healthy cities. Milton Keynes, UK: Open University Press, 1991.

\section{Health and greening the city}

\section{J McKenna}

\section{New visions for health promoters}

$\mathrm{T}$ he paper from Takano et al, ${ }^{1}$ outlines how the presence of a "green and pleasant land" has meaning even within an urban sprawl. Here, just perceiving that your neighbourhood is both green and pleasant was associated with increased longevity in older people. This is an important finding for at least two reasons. Firstly, it supports the qualitative sense that attractive spaces (however "attractiveness" is determined) and community amenities are just "good for us", without knowing why. The second reason is that it adds to the literature describing which environmental elements influence human life. This is expressed in academic domains variously labelled as spatial geography, urban planning, ecological health promotion, and lifecourse (and potentially behavioural) epidemiology.

Vitally, the study puts flesh on the bones of the old adage, "Build it and they will come". Certainly the study places a value and a direction on the first part of the injunction-build green urban spaces and wide paths for walking. This has direct relevance to health indices for older adults, and other researchers must establish the value of these, and other, urban features in different populations and cultures. Health promoters should take note; the study suggests that you can widen your remit to form alliances with urban planners to influence the conceptualisation and delivery of urban development.

However, Tanaka et al, haven't found evidence that once it is built, that they will come. That responsibility will fall to health promoters who promote the features of the urban environment to enhance individual health. There are many international groups, but in the UK this study speaks to the likes of Kerr et $a l,{ }^{2}$ and Mutrie et al, who have all been concerned to promote the use of urban facilities to increase levels of daily physical activity. Others, like SUSTRANS, have been concerned to create improved urban access by building much needed bridges, walkways, or cycle paths. For us advocates of the "good thing", we wish you well and hope that what you develop meets our own versions of what is green, wide, and walkable.

J Epidemiol Community Health 2002;56:896

\section{Author's affiliations}

J McKenna, Department of Exercise and Health Sciences, Centre for Sport, Exercise and Health, University of Bristol, Tyndall Avenue, Bristol BS8 ITP, UK

Correspondence to: Dr J McKenna; jim.mckenna@bristol.ac.uk

\section{REFERENCES}

1 Takano T, Nakamura K, Watanabe $M$ Urban residential environments and senior citizens' longevity in megacity areas: the importance of walkable green spaces. J Epidemiol Community Health 2002;56:913-18.

2 Kerr J, Eves F, Carroll D. Posters can prompt less active individuals to use the stairs. J Epidemiol Community Health 2000;54:942-3.

3 Mutrie N, Carney C, Blamey A. "Walk in to Work Out": a randomised controlled trial of self help intervention to promote active commuting. J Epidemiol Community Health 2002;56:407-12 


\section{Health and greening the city}

\section{Duhl}

\section{Relation of urban planning and health}

$\mathrm{T}$ his is an unusual paper, as the subject, the relation of open green space and health has rarely been studied. ${ }^{1}$ It is extremely well done.

In the 1960s, at a meeting of the Outdoor Recreation Resources Commission, an interdisciplinary panel of experts, declared open space was tremendously important, but there were no data. Indeed, as Abel Wollman, a Professor at Johns Hopkins School of Public Health said in the 1960s, "This is an important area, even if there is no data. Therefore, we must yell loudly!"
There are many studies of the commons, or piazzas that show how open space encourage interaction, communication, recreation, play, and much more. There is little specifically on closeness of open space to living, and its impact. Studies of outdoor activities such as running and walking similarly, as do those of recreation and aging show positive health impacts.

There is a dirth of literature on the relation of physical space to health. My summary of the relation of urban planning reviews to health shows how many planning issues effect safety, child rearing, recreation, and much more. ${ }^{2}$ What is not shown is Takano's conclusion of its importance in a neighbourhood.

I suggest that others take on this area of study.

J Epidemiol Community Health 2002;56:897

\section{Author's affiliations}

L Duhl, Public Health and Urban Policy, University of California, 410 Warren Hall no 7360, Berkeley, CA 94720-7360, USA

Correspondence to: Professor L Duhl; len-duhl@socrates.berkeley.edu

\section{REFERENCES}

1 Takano T, Nakamura K, Watanabe M Urban residential environments and senior citizens' longevity in megacity areas: the importance of walkable green spaces. J Epidemiol Community Health 2002;56:913-18.

2 Duhl LJ, Sanchez AK. Healthy cities and the city planning process: a background document on links between health and urban planning. EUR/ICP/CHDV 030403 (available from WHO.Euro or their web site)

\section{Health and greening the city}

\section{F Baum}

\section{Setting for health promotion: the importance for an evidence base}

$\mathrm{F}$ or some time epidemiology has been criticised for focusing almost exclusively on individual disease risk factors. Thus Shy ${ }^{1}$ maintains that academic epidemiology has served clinical medicine well because of its narrow biomedical perspective, dealing with risk factor and disease associations, rather than contributing to a population understanding of disease patterns. Others have been critical of this biomedical individualism and pointed to the lack of social, economic, environmental, and political analysis. ${ }^{23}$ In particular Rose has urged the need to recognise the crucial but subtle difference between sick individuals and sick populations. He suggested that epidemiology should understand disease as a consequence of how society is organised and behaves, what impact social and economic forces have on incidence rates, and what community actions will be effective in changing incidence rates. Epidemiology has been the main scientific method of public health and criticism of its individualism has led to calls for a new public health ${ }^{45}$ that sees understanding the social, environmental, and economic determinants of health as crucial. Epidemiologists are beginning to respond to the needs of the new public health and to examine the impact of locational and environmental factors. Thus in terms of health inequities epidemiologists are examining whether these reflect purely the characteristics of individuals or their households or whether they may also reflect the particular contexts in which people live. ${ }^{67}$ The paper by Takano et $a l^{8}$ looks beyond individual risk factors to features of environments and locations that affect health. This was done through a study of longevity in senior citizens that found a correlation between longevity (probability of five year survivial), whether they reported they had space for taking a stroll near their residence, parks, and tree lined streets near their residence. This correlation remained after controlling for the effects of the residents' age, sex, marital status, and socioeconomic status. The findings from the paper by Takano et al are important for three reasons: they demonstrate how epidemiological methods can be adapted to research the structural factors that affect people's health; they suggest that exercise patterns reflect the environments in which people live; and they contribute to an evidence base for health promotion initiatives based on settings such as Healthy Cities projects The first of these factors has been examined above; the other two are examined below.

Before the publication of the Ottawa Charter ${ }^{9}$ much health promotion put emphasis on changing behaviours of individuals. Many heart health campaigns were launched to try and persuade people to take up healthy behaviours. The results from these trials were largely disappointing and those who benefited tended to be better off and healthier people. For many people structural factors such access to healthy food, access to sporting facilities, or time limitation impeded lifestyle change. The paper by Takano et al provides important evidence that it is not individual motivation alone that determines willingness to take exercise but that the environments in which people live also have an effect.

The recognition of the limitation of behavioural health promotion has meant a greater focus on the settings in which people live, work, and play. Health promotion bodies, such as the National Heart Foundation in Australia, are moving away from a focus on the behaviour of individuals to look at the role of local environments in encouraging behaviours such as exercise. ${ }^{10}$ The WHO Healthy Cities movement ${ }^{11}$ has advocated the importance of working with 
local governments to take a whole of community approach to health promotion. These projects put considerable emphasis on gaining political support and mobilising community action to ensure that health becomes a key consideration in city and community decision making. The initiatives offer particular challenges to evaluators. They are long term and aim to influence health by changing the way decisions are made to make environments more supportive of health. Attributing causality in Healthy Cities projects is extremely difficult so while process evaluations of the projects have been conducted outcome evaluation has proved more difficult. Work such as that presented by Takano et al is very important in building an evidence base for Healthy Cities and other projects. A body of evidence that shows the ways in which availability of facilities affects the extent to which people exercise can form the basis of healthy urban planning decisions and will make the task of health promoters easier.

$J$ Epidemiol Community Health

2002;56:897-898

\section{Author's affiliations}

F Baum, South Australian Community Health Research Unit/Department of Public Health, Flinders University, GPO 2100 Adelaide, Australia

Correspondence to: Professor F Baum; fran.baum@flinders.edu.au

\section{REFERENCES}

1 Shy $\mathrm{CM}$. The failure of academic epidemiology: witness for the prosecution. Am J Epidemiol 1997; 145:479-84

2 Rose G. The strategy of preventive medicine. Oxford: Oxford University Press, 1992.

3 Krieger N. Epidemiology and the web of causation: has anyone seen the spider? Soc Sci Med 1994;39:887-903.

4 Ashton J, Seymour H. The new public health. Milton Keynes: Open University Press, 1988.
5 Baum F. The new public health. Melbourne: Oxford University Press, 2002 2nd edn.

6 Kawachi I, Kennedy B. Social capital and self-rated health: a contextual analysis. Am J Public Health 1999;89:1 187-93.

7 Maclntyre S, Ellaway A. Ecological approaches: rediscovering the role of the physical and social environment. In: Berkman L, Kawachi I, eds. Social epidemiology. Oxford: Oxford University Press:2000:33248.

8 Takano T, Nakamura K, Watanabe M Urban residential environments and senior citizens; longeveity in megacity areas: the importance of walkable green spaces. J Epidemiol Community Health 2002;56:913-18.

9 World Health Organisation. Ottawa Charter for Health Promotion. Health Promotion 1986:1:i-v.

10 MacDougall C, Wright C, Atkinson R. Supportive environments for physical activity and the local government agenda: a South Australian example. Australian Health Review 2002;24:178-84.

11 Tsouros A. The WHO Healthy Cities project: state of the art and future plans. Health Promotion International 1995;10:133-41. 